\title{
Ethnicity and Entrepreneurial Motive Differences: A South African Case Study
}

\author{
Akwasi Arko-Achemfuor \\ University of South Africa, aachea@unisa.ac.za;
}

\section{Dennis Yao Dzansi}

Central University of Technology, ddzansi@cut.ac.za

\author{
Doi:10.5901/mjss.2014.v5n14p228
}

\begin{abstract}
South Africa is often referred to as the rainbow nation because of its diversity in race, culture, ethnicity, language and other social discriminants. Meanwhile, diversity usually reflects in behaviour, attitudes and other human characteristics. Thus, ethnic diversity in South Africa should expectedly reflect in the entrepreneurial behaviour, attitudes, and motives of the different ethnic groups. This research explored the entrepreneurial motives of four ethic groups in a local municipality of South Africa to determine if there are significant differences. In this study, survey data was used to compare the motives that Tswanas, Afrikaners, Coloureds and Indians assign for engaging in entrepreneurial activities. The findings indicate that the four ethic groups differ significantly in entrepreneurial motives. Based on the findings, the researchers make recommendations to guide government, NGOs, development practitioners and all interested parties for promoting entrepreneurship among the different ethnic groups in South Africa.
\end{abstract}

Keywords: Entrepreneurship, motives, ethnicity, diversity, behaviour, attitudes

\section{Introduction and Background}

South Africa is often referred to as the rainbow nation because of its diversity in race, culture, ethnicity, language and other social discriminants. Meanwhile, diversity usually reflects in behaviour, attitudes and other human characteristics. Thus it is reasonable to expect that ethnic diversity in South Africa should in all probability. Herrington et al. (2009) pointed out in the 2009 Global Entrepreneurship Monitor (GEM) Report on South Africa that South African Indians and Whites are more likely to start businesses than Blacks and Coloureds. This assertion comes amidst entrepreneurship being seen as key to economic participation of all citizens of countries especially the developing ones. In fact, more and more countries, particularly ethnically diversified ones from both developed and developing including South Africa are now considering entrepreneurship among all ethnic groups as a major issue when formulating inclusive economic participation policies. But to succeed in promoting entrepreneurship among diverse ethnic groups it is fundamental that a thorough understanding of the attitudes and behaviours ethnic groups towards entrepreneurship is required. Therefore, developing an effective environment in which entrepreneurs can thrive for all ethnic groups in South Africa requires knowledge of how each ethnic background impacts on socio-economic outcomes. However, besides what Herrington et al. (2009) alluded to above, little is known about how ethnic background influences entrepreneurial motives, behaviour, attitude and success among the different ethnic groups in South Africa. A study on entrepreneurial motives of the major ethnic groups of South Africa is therefore imperative.

\subsection{Problem statement}

Entrepreneurship is increasingly seen all over the world as key to the economic participation of all people in their countries' economy. More and more countries are now considering inclusive entrepreneurship among all citizens when formulating inclusive economic participation policies. To successfully promote entrepreneurship among diverse ethnic groups necessitates an understanding of the attitudes and behaviours of these ethnic groups towards entrepreneurship. Thus, to develop an effective entrepreneurship environment in which all the people of South Africa can participate, there is a need gain thorough knowledge on how the various ethnic backgrounds of citizens impacts on entrepreneurship. This knowledge is unfortunately lacking in South Africa. In fact, Rwigema et al. (2012) alluded that South Africa's culturally varied society with diverse ethnicity, may help explain citizen's proclivity towards entrepreneurship. A casual observation 
across South Africa in general and in the NLM in particular, suggests some trends in the entrepreneurial tendency of the different ethnic groups. This paper explores the motives that the four ethnic groups in Naledi Local Municipality in the North West Province of South Africa mostly assign for engaging in entrepreneurial activities. The study uses the quantitative approach through a survey to compare the motives' Tswanas, Afrikaners, Coloureds and Indians assign for engaging entrepreneurial activities. The problem focused on in this study is summarised by the question, how does ethnicity influence entrepreneurial motives of South Africa's ethnic groups in the Naledi Local Municipal Area?

\subsection{Hypotheses}

The maim hypothesis of the study is: There are no significant differences in owner's motives for venturing into entrepreneurship based on ethnicity. Ten different motives were investigated. These include:

- To gain recognition and have influence in community.

- To promote welfare of my community \& ethnic group.

- To achieve something.

- To develop an idea for a product/business.

- To survive.

- To have access to resources.

- To have greater flexibility for private life.

- To have freedom to adapt my own approach to work.

- To escape frustration in my previous job.

- To give myself and my family security.

The ten motives led to the following ten hypotheses being tested to validate the main hypothesis.

$\mathrm{H} 10$ : There are no significant differences in owner's motive - to gain recognition and have influence in community.

$\mathrm{H} 20$ : There are no significant differences in owner's motive - to promote welfare of my community \& ethnic group.

$\mathrm{H} 30$ : There are no significant differences in owner's motive - to achieve something.

$\mathrm{H} 40$ : There are no significant differences in owner's motive - to develop an idea for a product/business.

$\mathrm{H} 50$ : There are no significant differences in owner's motive - to survive.

H6o: There are no significant differences in owner's motive - to have access to resources.

$\mathrm{H} 70$ : There are no significant differences in owner's motive - to have greater flexibility for private life.

$\mathrm{H} 8$ : There are no significant differences in owner's motive - to have freedom to adapt my own approach to work.

$\mathrm{H} 9_{0}$ : There are no significant differences in owner's motive - to escape frustration in my previous job.

$\mathrm{H} 100$ : There are no significant differences in owner's motive - to give myself and my family security.

\section{Objectives}

The main objective of the study is to investigate how ethnicity influences entrepreneurial motives in the research locale by testing the above listed hypotheses.

\section{Literature Review}

For convenience, entrepreneurship is broadly classified into two main theoretical fronts namely: psycho-personal and sociological approaches in this study. From this stand point, one can say that the earliest works on entrepreneurship were focused on a person's psychological and personal attributes as the determining factors in the decision to seek and exploit entrepreneurial opportunity (Lanza, 2004). In spite of its strong appeal, the psycho-personal perspective attracted several criticisms. For example, Robson (2001) described it as being one sided because it does not take into account important factors such as the social, economic and the legal frameworks that impact on entrepreneurship, even less does it take account of the interactions amongst the complex adaptive system of the environment in which such persons operate. For Robson (2001), the psycho-personal approach is outdated in the twenty first century.

\subsection{Sociological approach}

Proponents of sociological approach stress the social dimension in which entrepreneurship takes place. Simpeh (2011) identifies social networks; life course stage; ethnic identification; and population ecology as the four social contexts for 
identifying and pursuing entrepreneurial opportunities. According to Simpeh (2011), social networks deal with social relationships that help build trust and cohesion that are essential for running a successful venture. The life course stage is about life experiences that make individuals decide on an entrepreneurial career while ethnic identification concerns one's ethnic or sociological background which serves as "push" or "pull" factor to seek entrepreneurship careers. Population ecology examines the environmental conditions, including political, legal and environmental ones, together with market environments, that impact on the survival of businesses.

Sociological theories are quite relevant to explaining entrepreneurship in the multi ethnic South African environment as social networks can be used by the different ethnic groups in their business practices. For example, businesses operating in ethnic markets are bound to require trust on the part of both the business and its customers. It can also reasonably be expected that all or most ethnic groups depend to a large extent on their networks to secure and maintain their markets. The life course idea according to Jayawarna, Rouse and Macpherson (2007) typically focuses on the interplay between situation of biography regarding 'how the particularities of one's social location give rise to models of adaptation' can be used to explain why some of the different ethnic groups in South Africa embark on entrepreneurship as a career choice. For example, for Blacks and Coloureds, the introduction of democracy has opened up the opportunity for them to engage in legitimate economic activities. The ethnic identification theory according to Volery (2007:31) can also explain why people from the different ethnic backgrounds are either pulled or pushed into entrepreneurship. As discussed earlier, many Blacks and Coloureds are being pushed into entrepreneurship as a last resort, whereas whites appear to be pulled into entrepreneurship.

\subsection{Psycho-personal approach}

As stated above, proponents of this approach focus on a person's psychological and personal attributes as the determining factors in the decision to seek and exploit entrepreneurial opportunity (Lanza, 2004). Located within this broad ambit of psycho-personal theories on entrepreneurship are the motivation theories. Generally, theories of motivation are premised on the assumption that the motivational systems of an individual have decisive influence on behaviour. In this sense, motivation is a precondition for all human actions. The decision and the action for becoming an entrepreneur is therefore an outcome of entrepreneurial motivation. So, in analysing entrepreneurial motives or motivation, we search for reasons for the behaviour of individual entrepreneurs.

This paper is underpinned by the motivational theories of (Maslow, 1970; Herzberg, 1959; McGregor, 1960 and McClelland, 1961). Abraham Maslow came up with the hierarchy of needs theory of motivation. The hierarchy from bottom up are physiological needs, social needs, respect needs and self-actualisation needs. Maslow's (1970) theory explains that both the biological and the higher level needs guide peoples' functions. McClelland's achievement motivation theory posits that human needs are attached to life's concrete plans such as work, education, family etc. The plans and goals of an individual reflect values and when the results from certain actions or processes change the goals, the change pressures also target the values. Achievement motivation has been used to explain the behaviours of successful entrepreneurs. Some of the elements of achievement motivation include the desire for self-fulfilment, success and the drive to take responsibility of one's actions and inactions. McGregor's (1960) $X$ and $Y$ theory are based on the assumption that human beings are inherently lazy and are willing to work only when they are 'forced' or he lacks something, or on the other hand his perception of working and motives derive from one's own positive desire to work and perform. Relating motives to entrepreneurship, Ruohotie (1998) avers that entrepreneurship may be supported at the same time by performance motive and desire for power. Ruohotie (1988) points out that human motive can be divided into instrumental, expressive and mental growth motives. Entrepreneurs are particularly are seen to be have expressive motives (independence, individuality, job satisfaction) as dominant. Also, mental growth motives which include the desire to improve one's own ideas, innovation, and creativity are important for entrepreneurship. Herzberg (1974) on the other hand came up with the Two-Factor Theory which puts emphasis on what is normally referred to as circumstances and motivational factors. The main thesis of the Two-Factor Theory is that, satisfied factors motivate effective performances, whereas dissatisfied factors do not. The theory looks at two main dimensions of work, which are the work's external circumstances and work itself. Some of the motivational factors that contribute to satisfaction include achievement, rewards, responsibility, progress or mental growth.

All of these psycho-personal theories are relevant and applicable in most instances to determining entrepreneurial motives. For example, Maslow's (1970) theory could be used to understand why some ethnic groups venture into entrepreneurship (necessity and others for achievement and innovation). McGregor's (1960) Theory X and theory $Y$ are applicable to ethnic entrepreneurship as they appear to have expressive motives (independence, individuality, job satisfaction) as well as mental growth motives which include the desire to improve one's own ideas, creativity etc. which 
are some of the main characteristics of entrepreneurs in general. McClelland's (1961) achievement motivation theory places emphasis on value complex which appears to resonate with successful entrepreneurs including ethic entrepreneurs. Some of the elements of the desire to perform include the desire for self-fulfilment and internal locus of control including taking calculated risks in business.

\section{Methodology}

Ontologically the research is based on objective reality. Thus epistemologically, the study was conducted according to the positivist epistemology. A positivist epistemology requires deductive reasoning which means developing and testing hypotheses (Wilson, 2010; Du Plooy, 2002). Consistent with this philosophical leaning, the current study collected and analysed quantitative sample data to determine relationships (Wilson, 2010). Hypothetico-deductive reasoning was used to come to conclusions about the population based on sample data. Specifically, hypotheses were developed and tested using sample data to investigate the relationship between ethnicity and entrepreneurial motives among Tswanas, Afrikaners, Coloured and Indians in the Naledi Local Municipality. As stated earlier, the null hypothesis was $H_{0}$ there are no significant differences in owner's motives for venturing into entrepreneurship based on ethnicity with the alternate hypothesis being $H_{a}$ : there are significant differences in owners motives for venturing into entrepreneurship based on ethnicity.

\subsection{Target population}

The target population - the group of cases of interest (Wilson, 2010; Israel, 2008) for this study was all SMMEs in the Naledi Local Municipality in the North West Province of South Africa. It is from this population that a sample of 400 SMMEs was drawn. The unit of analysis is therefore the SMME. Because SMMEs have been defined by different interest groups around the world in diverse ways, it is important to set some criteria for businesses that have been included in the study as an SMME. In this study, SMME refers to a business that employs at least one other person in addition to the owner or manager and has a formal place of operation. Such an SMME should have some degree of permanency and a place for transacting their activities.

\subsection{Sampling}

Sampling is a process of systematically selecting cases or respondents for inclusion in a research study such that the sample is representative of the entire population. These cases are selected from a sample frame - the list of accessible population members from which a researcher can draw a sample (Wilson, 2010). Wilson (2010) points out that access to a concrete sample frame often compels researchers to compile their own. The absence of a reliable database for SMMEs in the North West Province was confirmed by Africa (2007). To overcome this difficulty, the researchers compiled own sample frame. In all, a total of 3522 SMMEs were identified from which a sample of 400 SMMEs were chosen.

Determining a sample size for research is complex and depends on a number of factors including comparative sample size of similar studies, margin of error to be tolerated, type of analysis to be done but to a greater extent is influenced by one's research philosophy (Wilson, 2010). The authors argue that if one adopts a positivist stance, then there is a need to select a large sample size enough to allow for statistical analysis. Leedy and Ormrod (2005) suggest that where the population is less than 100 , one should survey the whole population); if the population size is around 500 , then $50 \%$ of it should be sampled; if the population size is around 1,500, then $20 \%$ is recommended and beyond 5,000 or more units, a sample size of 400 is enough. Selecting a sample size of 400 was influenced by practical considerations of time and finance available and at the same time, considering the population of 3522 SMMEs, a sample of 400 was considered large enough based on the suggestion above.

Non-proportional as opposed to proportional stratified random sampling technique was used to select the 400 SMMEs. Stratified random sampling allows populations to be segmented into several mutually exclusive sub-populations or strata (Blumberg, Cooper \& Schindler, 2008). This technique allows for items to be selected from each sub group to ensure representativity (Wilson, 2010). Non-proportional stratified sampling avoided the situation where some of the ethnic groups could have been over represented while others would have very few or not feature at all. In this study, the strata included four distinct ethnic groups - Tswanas, Afrikaners, Coloureds and Indians. The different ethnic groups differ in population, location of their businesses, culture and so on. It was therefore important that a technique that ensures each segment of the sub-groups is represented was applied. After the SMMEs from the four stratified according to ethnic groups, an assistant picked participants from a box one at a time. Each time a participant was selected, it was not 
returned to the box until the required number for the group was obtained. The same procedure was used for the rest of the groups in the other boxes until the required sample size for each ethnic group has been reached.

\subsection{Data collection and analysis}

Three main tools for primary data collection are interviews, questionnaires and observation but the questionnaire is by far the most common (Parente, 2000) because it can be sent to many people regardless of location. Parente (2000) adds that questionnaires are a powerful tool in survey research which allows one to measure a person's thoughts, attitudes, opinions, experiences, likes and dislikes, just to name a few. A structured questionnaire was used in this study to collect primary data for analysis.

\section{Data Analysis and Results}

The researchers wanted to know whether ethnicity (independent variables) influences owner's motives (dependent variables) for starting own business in the South African context. Ten hypotheses linked to the ten different motives were tested in order to validate the main hypothesis $H_{0}$ : there are no significant differences in owner's motives for venturing into entrepreneurship based on ethnicity with the alternate hypothesis being $\mathrm{H}_{a}$ : there are significant differences in owners motives for venturing into entrepreneurship based on ethnicity. The data were analysed using SPSS version 21. Descriptive produced included frequency and percentage tables. The first inferential analysis performed to test the hypotheses was $X^{2}$ test. Significant differences were found for all the ten motives hence $H 1_{0}$ up to $H 10_{0}$ were all rejected and their alternative hypotheses accepted. But $X^{2}$ only indicates differences and does not tell the nature of difference. Therefore, the observed differences in motives are further explored through the Kendall's tau - $b\left(T_{B}\right)$ and the cross-tabs. $T B$ is a correlation coefficient that indicates the strength of dependence (correlation) between two variables. Kendall's tau - $b$ is used for determining effect size and direction. The coefficient ranges from -1 to +1 and is one of the non-parametric statistical tests that can be used when data is categorical. A rule of thumb is that $\tau_{B} \geq \pm 0.5=$ strong dependence; $\tau_{B}<$ \pm 0.5 but up to \pm 0.25 means moderate dependence; $\tau_{B}< \pm 0.25$ but $\neq 0$ means weak dependence; and $\tau_{B}=0$ means no dependence. The results are displayed in Tables 1 to 10 and are now discussed.

\subsection{Motive 1: To gain recognition and have influence in community}

In Table 1, $\mathrm{P}<0.05$ for the $\mathrm{X}^{2}$ test. Therefore, we reject $H 1_{0}$ and accept $H 1_{a}$. This simply means that there is a difference among ethnic groups in terms of level of agreement with to gain recognition and have influence in community as a reason for starting business. Table 1 shows that $\tau_{B}=-0.644$. This means a strong negative dependence. The patterns revealed by cross-tab in Table 1 implies that for Tswanas, and to some extent Coloureds, to gain recognition and have influence in community is an important motivating factor for engaging in entrepreneurship while for Afrikaner and Indian this is not the case. A possible explanation is the role of community in the cultural settings of different ethnic groups.

Table 1: Ethnic group of origin versus to gain recognition and have influence in community

\begin{tabular}{|c|c|c|c|c|c|c|}
\hline \multirow{2}{*}{ Ethnic group } & \multicolumn{5}{|c|}{ To gain recognition and have influence in community } & \multirow{2}{*}{ Total } \\
\hline & Strongly disagree & Disagree & Undecided & Agree & Strongly agree & \\
\hline Tswana & $0.0 \%$ & $2.7 \%$ & $10.1 \%$ & $67.7 \%$ & $19.5 \%$ & $100.0 \%$ \\
\hline Coloured & $0.0 \%$ & $0.0 \%$ & $55.0 \%$ & $45.0 \%$ & $0.0 \%$ & $100.0 \%$ \\
\hline Afrikaner & $15.4 \%$ & $69.2 \%$ & $15.4 \%$ & $0.0 \%$ & $0.0 \%$ & $100.0 \%$ \\
\hline Indian & $4.5 \%$ & $86.4 \%$ & $9.1 \%$ & $0.0 \%$ & $0.0 \%$ & $100.0 \%$ \\
\hline
\end{tabular}

\begin{tabular}{|c|c|c|c|}
\hline \multicolumn{4}{|c|}{ Significance test results } \\
\hline \multirow{2}{*}{ Pearson Chi-Square } & Value & df & P value \\
\cline { 2 - 4 } & 298.160 & 12 & $.000^{\star}$ \\
\hline
\end{tabular}

\begin{tabular}{|c|c|c|c|c|}
\hline \multicolumn{5}{|c|}{ Symmetric measure } \\
\hline \multirow{2}{*}{ Kendall's tau } & Value & Asymp. Std. Error & Approx. T & Approx. Sig. \\
\cline { 2 - 5 } & -.644 & .028 & -12.370 & $.000^{\star}$ \\
\hline
\end{tabular}




\subsection{Motive 2: To promote welfare of my community and ethnic group}

In Table 2, $\mathrm{P}<0.05$ for the $\mathrm{X}^{2}$ test. So, we reject $\mathrm{H} 2_{0}$ and accept $\mathrm{H}_{\mathrm{a}}$. This means that there is a difference in level of agreement with to promote welfare of my community and ethnic group as a reason for business between respondents from different ethnic groups. Table 2 depicts that $T_{B}=-0.59$ meaning strong negative dependence. From the patterns revealed by cross-tab in Table 2, one can say: for most Tswanas (82.9\%) to promote welfare of my community and ethnic group is an important motivating factor for engaging in entrepreneurship while for most of the Afrikaner respondents and to some extent Indians this is not much the case. Coloureds do appear be influenced by community consideration. One possible explanation is similar to the argument advanced above that culture could be a possible reason.

Table 2: Ethnic group vs to promote welfare of my community \& ethnic group

\begin{tabular}{|c|c|c|c|c|c|c|c|c|}
\hline & \multicolumn{7}{|c|}{ To promote welfare of my community \& ethnic group } & \multirow{2}{*}{ Total } \\
\hline & \multicolumn{2}{|c|}{ Strongly disagree } & \multicolumn{2}{|c|}{ Disagre€ } & Undecided & Agree & Strongly agree & \\
\hline Tswana & \multicolumn{2}{|c|}{$0.0 \%$} & \multicolumn{2}{|c|}{$1.2 \%$} & $16.0 \%$ & $68.5 \%$ & $14.4 \%$ & $100.0 \%$ \\
\hline Coloured & \multicolumn{2}{|c|}{$0.0 \%$} & \multicolumn{2}{|c|}{$20.0 \%$} & $50.0 \%$ & $30.0 \%$ & $0.0 \%$ & $100.0 \%$ \\
\hline Afrikaner & \multicolumn{2}{|c|}{$0.0 \%$} & \multicolumn{2}{|c|}{$20.0 \%$} & $50.0 \%$ & $30.0 \%$ & $0.0 \%$ & $100.0 \%$ \\
\hline Indian & \multicolumn{2}{|c|}{$0.0 \%$} & 45.5 & $.5 \%$ & $36.4 \%$ & $18.2 \%$ & \multirow[t]{2}{*}{$0.0 \%$} & $100.0 \%$ \\
\hline \multicolumn{8}{|c|}{ Significance test results } & \\
\hline \multirow{2}{*}{\multicolumn{2}{|c|}{ Pearson Chi-Square }} & \multirow{2}{*}{\multicolumn{2}{|c|}{$\begin{array}{c}\text { Value } \\
272.941\end{array}$}} & \multirow{2}{*}{\multicolumn{2}{|c|}{$\frac{d f}{12}$}} & \multicolumn{2}{|c|}{$P$ value } & \\
\hline & & & & & & \multicolumn{2}{|c|}{$.000^{\star}$} & \\
\hline \multicolumn{9}{|c|}{ Symmetric measure } \\
\hline \multirow{2}{*}{\multicolumn{2}{|c|}{ Kendall's tau - b }} & Valu & \multirow{2}{*}{\multicolumn{3}{|c|}{\begin{tabular}{|c|} 
Asymp. Std. Error \\
.030
\end{tabular}}} & \multirow{2}{*}{$\begin{array}{c}\text { Approx. T } \\
-12.123\end{array}$} & \multirow{2}{*}{\multicolumn{2}{|c|}{ Approx. Sig. }} \\
\hline & & -.59 & & & & & & \\
\hline
\end{tabular}

\subsection{Motive 3: To achieve something}

Table 3 shows that $\mathrm{P}<0.05$ for the $\mathrm{X}^{2}$ test. We therefore reject $H 3_{0}$ and accept $H 3_{2}$. This means that there is a difference in level of agreement with to achieve something between respondents from different ethnic groups. In Table $3, T_{B}=0.285$ meaning moderately positive dependence. The patterns revealed by cross-tab in (Table 3 ) indicates that, to achieve something is an important motivating factor for engaging in entrepreneurship for all ethnic groups. However, Table 3 suggests that it is more important for Afrikaners and Indians than for Tswanas and Coloureds. It can therefore be said that need for achievement motivates the four ethnic group members to engage in entrepreneurship. However, this need appears higher in Afrikaners and Indians than for Tswanas and Coloureds.

Table 3: Ethnic group of origin vs to achieve something

\begin{tabular}{|c|c|c|c|c|c|c|c|c|}
\hline & \multicolumn{6}{|c|}{ To achieve something } & & \multirow[b]{2}{*}{ Total } \\
\hline & \multicolumn{2}{|c|}{ Strongly disagree } & Disagree & Undecided & \multirow{2}{*}{\multicolumn{2}{|c|}{$\frac{\text { Agree }}{85.2 \%}$}} & agree & \\
\hline Tswana & \multicolumn{2}{|c|}{$0.0 \%$} & $0.0 \%$ & $2.3 \%$ & & & $12.5 \%$ & $100.0 \%$ \\
\hline Coloured & \multicolumn{2}{|c|}{$0.0 \%$} & $0.0 \%$ & $5.0 \%$ & \multicolumn{2}{|l|}{$95.0 \%$} & $0.0 \%$ & $100.0 \%$ \\
\hline Afrikaner & \multirow{2}{*}{\multicolumn{2}{|c|}{$\begin{array}{l}0.0 \% \\
0.0 \%\end{array}$}} & $0.0 \%$ & $0.0 \%$ & \multicolumn{2}{|l|}{$43.6 \%$} & $56.4 \%$ & $100.0 \%$ \\
\hline Indian & & & $0.0 \%$ & $0.0 \%$ & $59.1 \%$ & & $40.9 \%$ & $100.0 \%$ \\
\hline \multicolumn{9}{|c|}{ Significance test results } \\
\hline \multirow{2}{*}{\multicolumn{2}{|c|}{ Pearson Chi-Square }} & $\mathrm{Va}$ & & & \multicolumn{3}{|c|}{$P$ value } & \\
\hline & & \multicolumn{2}{|c|}{56.051} & & \multicolumn{3}{|c|}{$.000^{*}$} & \\
\hline \multicolumn{9}{|c|}{ Symmetric measure } \\
\hline \multirow{2}{*}{\multicolumn{2}{|c|}{ Kendall's tau }} & \multirow{2}{*}{\multicolumn{2}{|c|}{ Value }} & p. Std. Error & \multirow{2}{*}{\multicolumn{2}{|c|}{$\begin{array}{c}\text { Approx. T } \\
4.491\end{array}$}} & \\
\hline & & & & .058 & & & \multicolumn{2}{|c|}{$.000^{*}$} \\
\hline
\end{tabular}

\subsection{Motive 4: To develop an idea for a product/business}

Table 4 shows that $\mathrm{P}<0.05$ for the $X^{2}$ test. So, we reject $H 40$ and accept $H 4$ a. This means that there is a statistically significant difference in level of agreement between the different ethnic groups with regard to the statement to develop an idea for a product/business as a motive for entering into business. In Table $4, \tau_{B}=0.396$ meaning moderate dependence. 
The patterns revealed by cross-tab in Table 4 suggests that for Afrikaners and Indians, to develop an idea for a product/business is an important motivating factor for engaging in entrepreneurship. Although most Tswanas (78.2\%) and Coloured (70\%) agreed with the statement, these percentages are relatively smaller than for Afrikaners and Indians. Moreover, more Afrikaners and Indians tended to strongly agree. This means that the opportunity to bring a product into the market motivated Indians and Afrikaners to enter self-employment than it does to Tswanas and Coloureds. This can be interpreted to mean that Indians and Afrikaners are more pulled towards self-employment in order to market a new product than Tswanas and Coloureds.

Table 4: Ethnic group of origin vs to develop an idea for a product/business

\begin{tabular}{|c|c|c|c|c|c|c|c|}
\hline & \multicolumn{6}{|c|}{ To develop an idea for a product/business } & \multirow{2}{*}{ Total } \\
\hline & \multicolumn{2}{|c|}{ Strongly disagree } & Disagree & Undecided & Agree & Strongly agree & \\
\hline Tswana & \multicolumn{2}{|c|}{$0.0 \%$} & $0.8 \%$ & $21.0 \%$ & $74.3 \%$ & $3.9 \%$ & $100.0 \%$ \\
\hline Coloured & \multicolumn{2}{|c|}{$0.0 \%$} & $0.0 \%$ & $30.0 \%$ & $70.0 \%$ & $0.0 \%$ & $100.0 \%$ \\
\hline Afrikaner & \multicolumn{2}{|c|}{$0.0 \%$} & $0.0 \%$ & $0.0 \%$ & $12.8 \%$ & $87.2 \%$ & $100.0 \%$ \\
\hline Indian & \multicolumn{2}{|c|}{$0.0 \%$} & $0.0 \%$ & $9.1 \%$ & $63.6 \%$ & $27.3 \%$ & $100.0 \%$ \\
\hline \multicolumn{8}{|c|}{ Significance test results } \\
\hline \multirow{2}{*}{\multicolumn{2}{|c|}{ Pearson Chi-Square }} & Value & & \multirow{2}{*}{$\frac{d f}{9}$} & \multicolumn{2}{|c|}{$P$ value } & \\
\hline & & \multicolumn{2}{|c|}{194.745} & & \multicolumn{2}{|c|}{$.000^{*}$} & \\
\hline \multicolumn{8}{|c|}{ Symmetric measure } \\
\hline \multirow{2}{*}{\multicolumn{2}{|c|}{ Kendall's tau }} & \multirow{2}{*}{$\begin{array}{l}\text { Value } \\
396\end{array}$} & \multirow{2}{*}{\multicolumn{2}{|c|}{$\begin{array}{c}\text { Asymp. Std. Error } \\
.050\end{array}$}} & \multirow{2}{*}{$\begin{array}{c}\text { Approx. T } \\
6.795\end{array}$} & \multicolumn{2}{|c|}{ Approx. Sig. } \\
\hline & & & & & & \multicolumn{2}{|c|}{$.000^{*}$} \\
\hline
\end{tabular}

\subsection{Motive 5: To survive}

In Table 5, $\mathrm{P}<0.05$ for the $X^{2}$ test. Therefore we reject $H 5_{0}$ and accept $H 5_{a}$. This means that there is a difference between respondents from different ethnic groups in level of agreement with regard to, to survive as a reason for business. Using percentage analysis one can notice the pattern in the ratings for each group (Table 5). In conjunction with $T_{B}=-.503$ meaning negative strong correlation, one can say: most of Tswanas and Coloureds agreed with the statement to survive. Very few Indians and no Afrikaner cited this as a motive for starting a business. The higher percentages among Afrikaners and Indians for strongly disagree and disagree means that survival is not a major motive for them starting their businesses. This means that Blacks and Coloureds are pushed into self-employment. This finding is very important because it corroborates the earlier finding in the previous section.

Table 5: Ethnic group of origin vs to survive

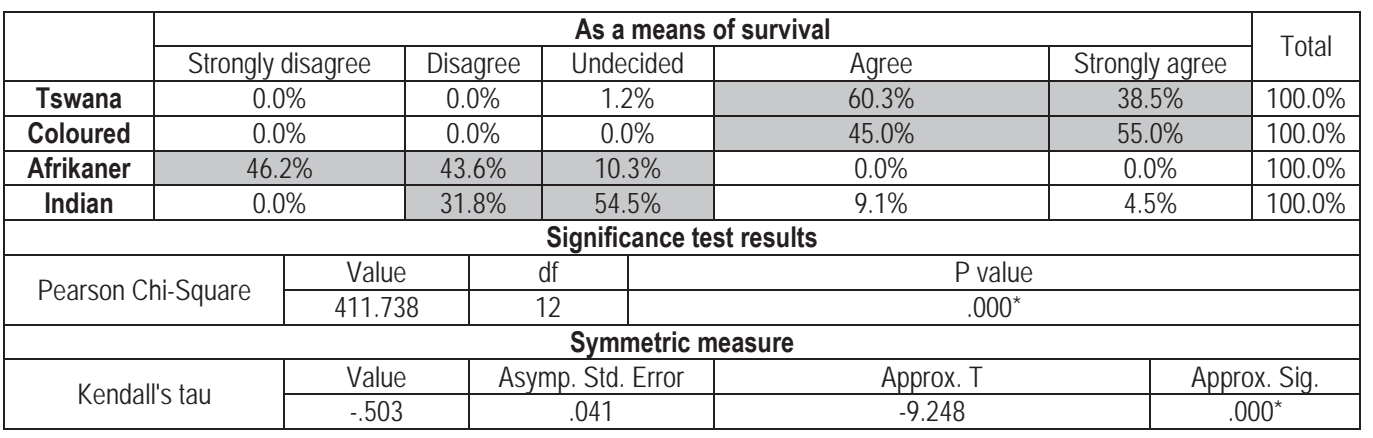

\subsection{Motive 6: To have access to resources}

Table 6 shows that $\mathrm{P}<0.05$ for the $X^{2}$ test. Therefore, we reject $H 6_{0}$ and accept $H 6_{a}$. This means that there is a difference in level of agreement with to have access to resources as a reason for business between respondents from different ethnic groups. From Table 6, $\tau_{B}=0.303$ meaning a moderate dependence. Using the percentages in Table 6 , one can notice a pattern in the ratings for each group (Table 6). From the cross-tabs in Table 6, one can say: 
to be more motivated by the desire to have freedom to adapt my own approach to work than Tswanas and Coloured.

Table 8: Ethnic group of origin vs to have freedom to adapt my own approach to work

\begin{tabular}{|c|c|c|c|c|c|c|c|c|}
\hline & \multicolumn{7}{|c|}{ To adapt my own approach to work } & \multirow{2}{*}{ Total } \\
\hline & \multicolumn{2}{|c|}{ Strongly disagree } & \multicolumn{2}{|c|}{ Disagree } & Undecided & \multicolumn{2}{|r|}{ Strongly agree } & \\
\hline Tswana & & & \multicolumn{2}{|c|}{$3.1 \%$} & $21.4 \%$ & $73.5 \%$ & $1.9 \%$ & $100.0 \%$ \\
\hline Coloured & & & \multicolumn{2}{|c|}{$5.0 \%$} & $35.0 \%$ & $55.0 \%$ & $5.0 \%$ & $100.0 \%$ \\
\hline Afrikaner & & & \multicolumn{2}{|c|}{$0.0 \%$} & $0.0 \%$ & $5.1 \%$ & $94.9 \%$ & $100.0 \%$ \\
\hline Indian & & & \multicolumn{2}{|c|}{$0.0 \%$} & $9.1 \%$ & $68.2 \%$ & $22.7 \%$ & $100.0 \%$ \\
\hline \multicolumn{9}{|c|}{ Significance test results } \\
\hline \multirow{2}{*}{\multicolumn{2}{|c|}{ Pearson Chi-Square }} & \multirow{2}{*}{\multicolumn{2}{|c|}{$247.520^{a}$}} & \multirow{2}{*}{\multicolumn{2}{|c|}{$\frac{d f}{9}$}} & \multicolumn{2}{|c|}{$P$ value } & \\
\hline & & & & & & \multicolumn{2}{|c|}{$.000^{*}$} & \\
\hline \multicolumn{9}{|c|}{ Symmetric measure } \\
\hline \multirow{2}{*}{\multicolumn{2}{|c|}{ Kendall's tau }} & \multirow{2}{*}{\multicolumn{2}{|c|}{$\begin{array}{c}\text { Value } \\
.410\end{array}$}} & \multirow{2}{*}{\multicolumn{2}{|c|}{$\begin{array}{c}\text { Asymp. Std. Error } \\
.050\end{array}$}} & \multirow{2}{*}{$\begin{array}{c}\text { Approx. T } \\
7.049\end{array}$} & \multicolumn{2}{|c|}{ Approx. Sig. } \\
\hline & & & & & & & & $00^{*}$ \\
\hline
\end{tabular}

\subsection{Motive 9: Frustrated in my previous job}

Table 9 shows that $\mathrm{P}<0.05$ for the $X^{2}$ test. So, we reject $H 9_{0}$ and accept $H 9_{a}$. This means that there is a difference in level of agreement between respondents from different ethnic groups with regard to frustrated in my previous job as a reason for business. Table 9 also shows that $\tau_{B}=-0.202$ meaning negatively weak dependence. Percentage analysis in Table 9 shows a pattern in the ratings for each group. Using the percentage analysis in Table 9, one can say that for most Tswanas and to some extent Coloureds, frustration with previous job is an important motivating factor for engaging in entrepreneurship while for Afrikaners and Indians this is not the case. A possible explanation could be that necessity drives most Coloured and Tswanas to entrepreneurship as against opportunity in the case of most Afrikaners and Indians.

Table 9: Ethnic group of origin vs frustrated in my previous job

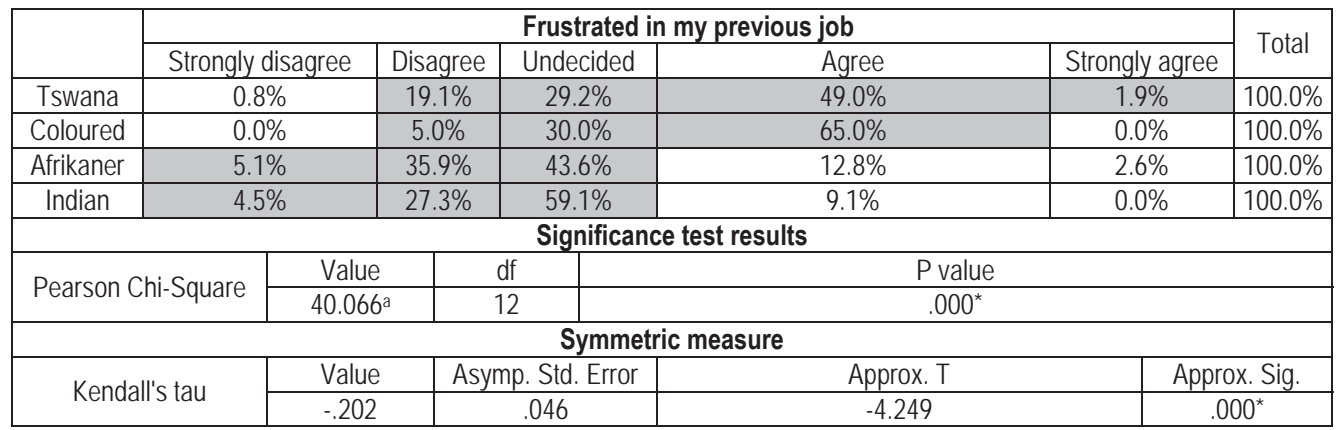

\subsection{Motive 10: to give myself and my family security}

Table 10 shows that $\mathrm{P}<0.05$ for the $\mathrm{X}^{2}$ test. So, we reject $H 10_{0}$ and accept $H 1 \mathrm{a}_{\mathrm{a}}$. This means that there is a difference between respondents from different ethnic group in level of agreement with respect to, to give myself and my family security as a reason for business $\mathrm{s}$. Table 10 shows that $\tau_{B}=0.068$ meaning very weak but positive difference. Using percentage analysis one can notice the pattern in the ratings for each group (Table 10). Table 10 shows that all the ethnic groups are motivated by the desire to give myself and my family security. Although there are differences, Table 10 shows that $T_{B}=0.068$ means the difference is very negligible as it tends to almost zero hence can be ignored. 
Table 10: Ethnic group of origin vs to give myself and my family security

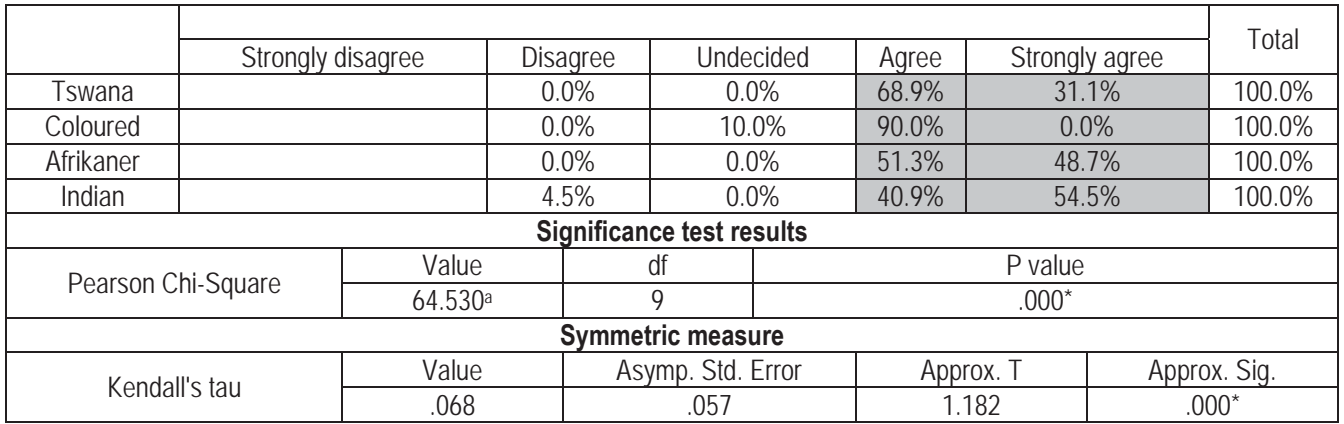

\section{Conclusion}

As stated elsewhere in this study, the objective of the study was to determine the impact (if any) which ethnicity has on the entrepreneurial motives among the different ethnic groups in the Naledi Local Municipality in the North West Province of South Africa and to make suggestions for enhancing entrepreneurship development in a multicultural South African setting. Ten hypotheses were tested to arrive at a conclusion. In each hypothesis, significantly different distinct patterns were found for owners from the different ethnic groups under study. Therefore we can reject $H_{0}$ and accept $H_{a}$ : There are significant differences in owners motives for venturing into entrepreneurship based on ethnicity. Consequently it is concluded that motives for venturing into entrepreneurship differ among the four ethnic groups Tswanas, Afrikaners, Coloureds and Indians.

In other words, this research has shown that ethnicity has great influence on entrepreneurship and in many ways concurs with views of other researchers. This finding is significant and consistent with a number of similar findings in the South African context. For example, Urban and Van Vuuren (2008) found significant differences in the entrepreneurial motivation of 210 MBA students from various South African ethnic groups. Similarly, Van Scheers (2010) also found motivational differences among South Africans of Asian, Indian and Black ethnicity. Lately, Farrington, Gray and Sharp (2012) also found that ethnicity influences choice of entrepreneurial career in South Africa. It is interesting to note that Basu and Altinay (2012) also found differences in entrepreneurial motives among six different ethnic groups of entrepreneurs from East Africa and East Asia in London. These differences could possibly be due to the different ethnic groups having different traditions and customs which are likely to contribute to differences in entrepreneurial behaviour (Mungai \& Ogot, 2010).

To conclude, Loucks (1981) notes that entrepreneurship is culture embedded and as a result called on researchers on entrepreneurship to be more interested in the cultural distinctions of the entrepreneurship phenomenon, and differences in how values, beliefs, attitudes, shared norms and particularity of conditions, influence what people do. The observation of Loucks is closely related to the views of Morrison (2000:64) who states that there is a significant relationship between entrepreneurship and cultural specificity, and if the discipline has to make progress, researchers should search more deeply into the differences, rather than focusing on similarities. The potential for and frequency of entrepreneurship has been shown to be associated with the occurrence of certain culture specific variables (Thomas \& Muller, 2000). Considering that many researchers have called for more focus on culture embeddedness of entrepreneurship, this study has made an important contribution to the literature because, ethnicity is a cultural issue just as race and language are.

\section{Recommendations}

The study found that entrepreneurial outcomes of Tswanas, Afrikaners, Coloureds and Indians in the NLM differed between the groups in terms of their motives for starting business. Afrikaner and Indian respondents to a large extent indicated that they were motivated more by the need to innovate; having the freedom to do what they enjoy and the flexibility entrepreneurship offers them to make more money. They found the business risks in entrepreneurship part of the normal processes of business. The Tswana and Coloured entrepreneurs on the other hand were mostly motivated by need to survive (entrepreneurship is the last resort) as they had nothing else to fall back on. They were also prepared to 
take up paid jobs if they could not find work anywhere rather than starting their own businesses. The differences that were found in entrepreneurial motives between Tswana, Afrikaner, Coloured and Indian entrepreneurs have both policy and research implications.

Firstly, the results suggest that Tswana's and by extension blacks engage in entrepreneurship mainly because they cannot find employment. The results also show that frustrations at previous employment forced most Blacks and Coloureds to take up self-employment than it did to Indians and Afrikaners. This implies predominance of necessity entrepreneurship among Blacks and Coloureds which does not augur well for real entrepreneurship development. On another note, it raises the pertinent question: does this mean that given a gainful employment, Blacks and Coloureds will not be motivated to establish and manage their own business? Supposing the answer is in the affirmative, it will mean that a lot of effort needs to be made by policy makers and entrepreneurship development agencies to develop the entrepreneurial spirit in the people from these ethnic groups.

Secondly, seeing that Blacks and Coloureds on the one hand display similar entrepreneurial motives that are different from Indians and Afrikaners on the other hand, policy makers and entrepreneurship development agencies in South Africa should take these differences into consideration when designing and rolling out training and development efforts if their efforts are to yield meaningful results.

\section{References}

Afrika, D.2007. Departmental budget speech 2007: North West Department of Economic Development and Tourism.

Basu, A. and Altinay, E. 2002.The interaction between culture and entrepreneurship in London's immigrant businesses. International Small Business Journal, Blumberg, B., Coopers, D.R. and Schindler, P. (2008) Business research methods. 2. European Edition. Berkshire: McGraw-Hill.

Blumberg, B., Coopers, D.R. and Schindler, P. (2008) Business research methods. 2. European Edition. Berkshire: McGraw-Hill.

Davidson, P. 1989. Continued entrepreneurship and small firm growth. Doctoral dissertation. Stockholm: EFI/Stockholm School of Economics.

Du Plooy, G.M. 2002. Communication research. Techniques, methods and applications. Kewyn: Juta

Dzansi, D.Y. 2004. Social responsibility of SMMEs in rural communities. Unpublished Doctoral thesis. Pretoria: University of Pretoria.

Farrington, S., Gray, B., and Sharp, G. 2012. The influence of gender and ethnicity on the perspectives of an entrepreneurial career in the South African context. The Southern African Journal of Entrepreneurship and Small Business Management, Vol 5 pp. 1-23.

Herrington, M., Kew, J. and Kew, P. 2009. Tracing entrepreneurship in South Africa. A GEM perspective. South African Report, 2009. Cape Town: UCT Graduate School of Business.

Herzberg, F. 1974. Motivation-hygiene profiles. Organisational Dynamics, 3(2): 18-29.

Israel, D. 2008. Data analysis in business research. A step-by-step non parametric approach. Los Angles: Response Business Books from SAGE.

Jayawarna, D., Rouse, J., and Macpherson, A. 2007. Pathways to entrepreneurship across the life course: An innovative model. Paper presented at the Institute for Small Business and Entrepreneurship, 7-9 November 2007, Glasgow, Scotland.

Lanza, A. 2004. Beyond pioneers and followers: A typology of entrepreneurial behaviours for hostile environments. In G. Corbetta, M. Huse and D. Ravasi (Eds). Crossroads of entrepreneurship, Boston: Kluwer Academic.

Leedy, P.D., and Ormord, J.E. 2005. Practical research. Planning and design. 8 ed. New Jersey: Pearson Merrill/ Prentice Hall.

Loucks, K.E. 1981. A survey of research on Small Business Management and Entrepreneurship in Canada. In Vesper, K. ed. Frontiers of Entrepreneurship Research. Wellesley, MA: Babson College, 111-129.

Maslow, A.H. 1970. Motivation and personality, $2^{\text {nd }}$ ed. New York: Harper and Row.

McClelland, D. 1961. The Achieving Society. Princeton, N.J. Van Nostrand.

McGregor, D. 1960. The human side of enterprise. Annotated edn. McGraw-Hill.

Moore, L.L., Grabsch, D.K., and Rotter, C. 2010. Using achievement motivation theory to explain student participation in a residential leadership learning community. Journal of Leadership Education, 9(2), 22-34.

Morrison, A. 2000. Entrepreneurship: What triggers it? International Journal of Entrepreneurial Behaviour and Research, 6(2): 59-71.

Ogot, E and Mungai, M. 2010. Ethnicity, Culture and Entrepreneurship. Paper Presented at the 1 st International Business Management (AIBUMA) Conference. Kenyatta International Convention Centre, Nairobi, 25-26 August 2010.

Parente, D. 2000. Advertising Campaign Strategy: A Guide of marketing communication plans. 2 ed. London: Harcourt College.

Robson, A. 2001. The Biological Basis of Economic Behaviours. Journal of Economic Literature, 39: 11-33.

Ruohotie, P. 1998. Motivaatio, thhato ja oppiminen. Oy Edita Ab. Helsinki.

Rwigema, R., Urban, B. and Venter, R. 2012. Entrepreneurship: Theory in Practice. 2 ed. Cape Town: Oxford University Press.

Shaver, K.G., and Scott, L.R. 1991. "Person, process, choice: The psychology of new venture creation". Entrepreneurship, Theory and Practice, 16 (Winter): 23-45.

Simpeh, K.N. 2011. Entrepreneurship Theories and Empirical Research: A Summary of the Literature. European Journal of Business Management. 3(6).

Solymossy, E. 1998. The Relationship of Individual, Venture, and Environmental Factors to Success. Unpublished Doctoral thesis 
submitted to the Cape Western University.

Thomas, A.S. and Muller, S.L. 2000. A Case Study for Comparative Entrepreneurship: Assessing the Relevance of Culture. Journal of International Business Studies, 31(2): 287-301.

Urban, B. \& Van Vuuren, J.J. 2008. Antecedents to entrepreneurial intentions: Testing for measurement invariance for cultural values, attitudes and self-efficacy beliefs across ethnic groups. SA Journal of Human Resource Management, 6(1):1-9.

Van Scheers, L. 2010. The role of Ethnicity and Culture in Developing Entrepreneurs in South Africa. Problems and Perspectives in Management, 8(4): 20-28.

Wilson, J. 2010. Essentials of business research. A guide to doing your research project. London: Sage Publications LTD. 